\title{
Association of PTPRD Gene Polymorphism and Non-small Cell Lung Cancer Risk
}

\author{
Tong Su MS ${ }^{1 \#, ~ Y a n ~ D u ~ P H ~}{ }^{1 \#}$, Lijun Zhao ${ }^{2 \#}$, Xiaojie Tan ${ }^{1}$, Wenjun Chang ${ }^{1}$, Hongwei Zhang ${ }^{1}$ and Guangwen Cao ${ }^{1 *}$ \\ ${ }^{1}$ Department of Epidemiology, Second Military Medical University, Shanghai 200433, China \\ ${ }^{2}$ Department of Pulmonary, Changhai Hospital, Second Military Medical University, Shanghai 200433, China \\ ${ }^{\#}$ The first 3 authors contributed equally to this article
}

Received: March 05, 2014 ; Accepted: April 08, 2014; Published: April 10, 2014

*Corresponding author: Guangwen Cao, MD, PhD, Department of Epidemiology, Second Military Medical University, 800 Xiangyin Rd, Shanghai 200433, China, Tel: +86-13818581631; Fax: +86-21-81871060; E-mail: gcao@smmu.edu.cn

\begin{abstract}
Background: Non-small-cell lung cancer (NSCLC) is one of the leading causes of cancer death worldwide. Genetic variations may play a role in NSCLC progression and prognosis.

Objective: This study investigated protein tyrosine phosphatase receptor delta (PTPRD) rs2279776 with NSCLC susceptibility, chemotherapy response and survival in a Chinese population.

Methods: A total of 352 cases and 704 controls were enrolled. Logistic regressions were used to evaluate the associations of genetic polymorphism with NSCLC risk and chemotherapy response. Overall survival was analyzed using the Kaplan-Meier method and the survival curves were compared with log-rank test. Subgroup analyses were also performed.

Results: PTPRD rs2279776 was significantly associated with NSCLC risk. Under the dominant model, rs2279776 minor allele carriers (GC+CC) had a significantly increased risk of NSCLC compared to major allele homozygotes (GG) $(P=0.01$, odds ratio $=1.38,95 \%$ confidence interval=1.07-1.79). The association remained significant after adjustment of covariates, and also in males and age $>60$ years subgroups. No association was observed between this polymorphism and chemotherapy response in advanced NSCLC patients. Survival analyses could not detect any effect of rs2279776 on NSCLC survival.
\end{abstract}

Conclusions: Genetic polymorphism of PTPRD gene could be valuable biomarker of NSCLC risk.

Keywords: Single-nucleotide polymorphism; PTPRD gene; Nonsmall cell lung cancer (NSCLC); Chemotherapy response; Survival

\section{Introduction}

Lung cancer is one of the leading causes of cancer mortality in both men and women worldwide [1]. Cigarette smoking is the main risk factor of lung cancer, however, only a fraction of smokers develop lung cancer during their lifetime. Non-small-cell lung cancer (NSCLC) accounts for approximately $85 \%$ of primary lung cancer, and about two thirds of NSCLC are diagnosed at an advanced stage[1]. Current standard therapies for NSCLC include surgical resection, platinum-based doublet chemotherapy, and radiation therapy alone or in combination. Unfortunately, these therapies rarely cure the disease, and the overall 5-year survival rate is still only about $16 \%$ [2]. Even for patients with early stage NSCLC, the long-term prognosis is not satisfactory, with a 5-year survival rate of less than 50\%[3]. Current evidence show that tumor-node-metastasis (TNM) staging system, age, performance status, and weight loss are prognostic factors of NSCLC survival, however only a small portion of the great variation of patient's survival can be explained by these factors. These suggest genetic variation including functional polymorphisms in important genes may play a role in lung cancer development, therapy response, and prognosis.

Protein tyrosine phosphatase receptor delta (PTPRD) was found to dephosphorylate the oncoprotein signal transducers and activators of transcription 3 (STAT3), and is a putative tumor suppressor that is frequently inactivated and mutated in multiple human cancers including lung cancer[4,5]. In this study, we selected PTPRD rs2279776, a SNP previously identified to be associated with clear cell renal cell carcinoma (ccRCC)[6]. We tested the association of this SNP with NSCLC risk, and further examined the effect of this polymorphism on chemotherapy response and survival of NSCLC patients.

\section{Materials and Methods}

\section{Study population}

From July 1997 to October 2008, patients with newly diagnosed and histopathologically confirmed primary NSCLC were enrolled at Changhai Hospital of the Second Military Medical University. The healthy controls were chosen from those who received routine physical examination at the Physical Examination Center of Changhai hospital during 2006-2011. Two controls for each case were randomly selected from possible controls by matching on sex and age at baseline ( \pm 2 years). The controls didn't have any lung-related diseases. Smoking status was categorized as never smoker (having smoked less than 100 cigarettes during lifetime) or ever smoker (current and exsmoker). In total, 352 cases and 704 controls were selected.

All participants were of ethnic Chinese origin. Written 
informed consent was obtained from each participant. The study protocol was approved by the Institutional Review Board at the Second Military Medical University and conformed to the ethical guidelines of the Declaration of Helsinki (2000).

\section{Data collection and follow-up}

Demographic and clinical data were obtained from the medical records. Of the 352 NSCLC patients, 161 (45.7\%) were advanced NSCLC patients receiving evaluable platinum-based chemotherapy. Chemotherapy regimens and drug dosages were: cisplatin (DDP) $75 \mathrm{mg} / \mathrm{m}^{2}$ on day 1 ; carboplatin (CBP) area under curve $($ AUC $)=5-6 \mathrm{~g}$ on day 1 ; gemcitabine $($ GEM) $1250 \mathrm{mg} /$ $\mathrm{m}^{2}$ on days 1 and 8; paclitaxel (TAX) $135 \sim 175 \mathrm{mg} / \mathrm{m}^{2}$ on day 1 (kept for $3 \mathrm{~h}$ ); docetaxel (DOC) $75 \mathrm{mg} / \mathrm{m}^{2}$ on day 1 (kept for 1 h); vinorelbine (NVB) $25 \mathrm{mg} / \mathrm{m}^{2}$ on days 1 and 8; or pemetrexed disodium (PEM) $500 \mathrm{mg} / \mathrm{m}^{2}$ on day 1 . All drugs were intravenous administrated every 3-4 weeks as a treatment cycle. Patients' response was assessed after 2 treatment cycles according to the Response Evaluation Criteria in Solid Tumors[7], which classified the response into complete response (CR), partial response (PR), stable disease (SD), and progressive disease (PD). CR and PR were considered as good response, and SD or PD as poor response.

Follow-up in the current study was started 2 months after the diagnosis. Follow-up was performed every 3 months by telephone or in-person interview at the outpatient clinic according to our standard epidemiological procedure.

\section{Genotyping}

Genomic DNA was isolated from peripheral blood using QIAmp DNA extraction kits (QIAGEN, Hilden, Germany). Genotypes were examined by fluorescent-probe real-time quantitative PCR (qPCR) in a LightCycler ${ }^{\mathrm{TM}} 480$ (Roche, Basel, Switzerland). Primers and probes (Taqman or Minor Groove Binder [MGB]) were designed and synthesized by GeneCore BioTechnologies (Shanghai, China). The sequences of primers and probes are forward primer, 5'- CCAAATGTTTCGGGGAGAGA-3'; reverse primer, 5'- CTGGTTGAATAACACTCCTTGTTTTC-3'; probe-1, FAM- TTCCTATAGCCATCTAT-MGB; probe-2, HEXTTCCTATACCCATCTAT-MGB. Each reaction mixture constituted of $0.2 \mu \mathrm{mol} / \mathrm{L}$ of primers, $0.2 \mu \mathrm{mol} / \mathrm{L}$ of probes, $0.1 \mu \mathrm{g}-0.5 \mu \mathrm{g}$ purified templates in Premix Ex Taq reaction system (Takara, Dalian, China). The reaction program was $95^{\circ} \mathrm{C}$ for $10 \mathrm{~s}$, followed by 40 cycles of $95^{\circ} \mathrm{C}$ for $10 \mathrm{~s}$, and $60^{\circ} \mathrm{C}$ for $30 \mathrm{~s}$. For quality control, $10 \%$ of the samples were randomly selected and genotyped twice, and the reproducibility was $100 \%$.

\section{Statistical analysis}

Hardy-Weinberg equilibrium (HWE) of the controls was tested by the exact test. Student's $t$-test or Pearson's chisquare test was used to compare demographic and clinical characteristics. Logistic regression analysis was performed to obtain odds ratios (ORs) and their 95\% confidence intervals (95\% CIs) for the associations of different patient characteristics including polymorphism rs2279776 genotypes with NSCLC risk and chemotherapy response. Overall survival (OS) was calculated from the time of definitive diagnosis to the date of death from any cause or last follow-up. Survival distributions were estimated using the Kaplan-Meier method and the survival curves were compared by the log-rank test. All statistical tests were twosided with a significance level at 0.05 . Statistical analyses were conducted using software SPSS (v16.0 for Windows, SPSS, Chicago, IL).

\section{Results}

\section{Patient characteristics}

The demographic and clinical characteristics of the cases and controls are shown in Table 1 . Of the 352 NSCLC cases, 10 $(2.8 \%)$ patients refused any treatment, and $25(7.1 \%)$ patients lost to follow up after the first treatment at Changhai Hospital. Of the remaining cases, $156(44.3 \%)$ were at the early stage and underwent surgical treatment, most of whom (120/156, 76.9\%) received preoperative or postoperative adjuvant chemotherapy. $161(45.7 \%)$ were advanced patients who didn't receive surgical operation but underwent platinum-based chemotherapy. In healthy controls, 492 (69.9\%) were males. The mean age of controls was 58.8 years ( $\mathrm{SD}=14.4$ years). There were no significant differences between cases and controls on sex $(P=1.00)$ and age $(P=0.38)$. There were less smokers in controls compared to cases $(19.0 \%$ vs. $51.7 \%, P<0.001)$.

Table 1: Population Characteristics.

Abbreviations: ECOG: Eastern Cooperative Oncology Group; SD: Standard Deviation. ${ }^{*} P$ values are derived by $x^{2}$ test; except for age where Wilcoxon rank sum test is used.

\begin{tabular}{|c|c|c|c|}
\hline Characteristic & Cases $(\mathrm{N}=352)$ & Controls $(\mathrm{N}=704)$ & $P^{*}$ \\
\hline Male, n (\%) & $246(69.9)$ & $492(69.9)$ & 1.00 \\
\hline Age (year) & & & 0.38 \\
\hline Mean \pm SD & $59.5 \pm 10.6$ & $58.8 \pm 14.4$ & \\
\hline Range & $26-90$ & & \\
\hline Smoking Status & & & $<0.001$ \\
\hline No & $170(48.3)$ & $570(81.0)$ & \\
\hline Yes & $182(51.7)$ & $134(19.0)$ & \\
\hline \multicolumn{4}{|l|}{ Histology, n (\%) } \\
\hline Adenocarcinoma & $181(51.4)$ & -- & \\
\hline Squamous cell carcinoma & $118(33.5)$ & -- & \\
\hline Large-cell carcinoma & $21(6.0)$ & -- & \\
\hline Other/Unspecified & $32(9.1)$ & -- & \\
\hline \multicolumn{4}{|l|}{ Stage, n (\%) } \\
\hline I & $53(15.1)$ & -- & \\
\hline II & $77(21.9)$ & -- & \\
\hline IIIA & $48(13.6)$ & -- & \\
\hline IIIB & $54(15.3)$ & -- & \\
\hline IV & $120(34.1)$ & -- & \\
\hline \multicolumn{4}{|l|}{$\begin{array}{c}\text { ECOG performance } \\
\text { status }\end{array}$} \\
\hline $0-1$ & $343(97.4)$ & -- & \\
\hline$\geq 2$ & $9(2.6)$ & -- & \\
\hline \multicolumn{4}{|l|}{ Radiation therapy } \\
\hline Never received & $246(69.9)$ & -- & \\
\hline Ever received & $106(30.1)$ & -- & \\
\hline
\end{tabular}




\section{Association of PTPRD SNP with NSCLC risk}

The allele frequency of PTPRD rs2279776 in controls was conformed to HWE $(P=0.125)$. Table 2 presents the genotype distributions of this SNP among the cases and controls and the association of rs2279776 with NSCLC. Under the dominant model, carriers of at least one minor allele $\mathrm{C}(\mathrm{GC}+\mathrm{CC})$ were associated with a significantly increased risk of NSCLC compared to major allele homozygotes (GG) $(P=0.01, \quad O R=1.38,95 \%$ $\mathrm{CI}=1.07-1.79)$. The association continued to be significant after adjusting for age and smoking status $(P=0.02$, adjusted $\mathrm{OR}=1.37$, 95\% CI=1.04-1.81). The allelic association test showed that the minor allele $\mathrm{C}$ of rs2279776 was associated with an increased risk of NSCLC $(P=0.02,0 R=1.28,95 \% \mathrm{CI}=1.05-1.55)$. However, the association was lost after adjustment of age and smoking status $(P=0.053)$. Smoking status was also associated with NSCLC risk $(P<0.0001,0 \mathrm{R}=4.55,95 \% \mathrm{CI}=3.44-6.03)$. For the stratified analyses, rs2279776 was significantly associated with the risk of NSCLC in males $(P=0.02, \mathrm{OR}=1.46,95 \% \mathrm{CI}=1.07-1.98)$ and age $>60$ years group $(P=0.01, \mathrm{OR}=1.62,95 \% \mathrm{CI}=1.12-2.36)$ (Table 3$)$. There were no significant interactions between rs2279776 and sex, age or smoking status $\left(P_{\text {interaction }}>0.05\right.$ for all).

\section{Associations of PTPRD SNP with chemotherapy response}

Of the 161 advanced NSCLC patients, the number of patients with CR, PR, SD or PD was $0,44,65$ and 52 , respectively. The overall response rate was $27.3 \%$ (44/161). Response rates were compared among different gender, age, smoking status, histology, stage, ECOG performance status, and radiation therapy groups. The response rate was significantly different between smoking status group (response rate, No vs. Yes: $19.2 \%$ vs. $34.1 \%, P=0.04$ ). However, no significant associations were detected between PTPRD genotypes and objective response (Table 4).

\section{Associations of PTPRD SNP with NSCLC prognosis}

The median follow-up time of this study was 20.8 months (range: 1.0 to 178.6 months). For early stage NSCLC patients, smoking status [median survival time (MST), No vs. Yes: 82.2 months vs. 45.6 months, $P=0.01]$ was significantly associated with OS (Table 5). In advanced NSCLC patients, smoking status (MST, No vs. Yes: 24.4 months vs. 16.8 months, $P=0.04$ ) and radiation therapy (MST, Never vs. Ever: 16.2 months vs. 24.3 months, $P=0.049$ ) were significantly associated with OS (Table 6). In general, no association was observed between PTPRD rs2279776 and OS, either in early or advanced NSCLC patients. No association was detected in further subgroup analyses.

\section{Discussion}

In this study, we evaluated relationships of PTPRD rs2279776 with the risk, chemotherapy response and prognosis of NSCLC in a Han Chinese population. We observed that under the dominant model PTPRD rs2279776 minor allele carriers (GC+CC) had a significantly increased risk of NSCLC. However, no association was observed between this SNP and chemotherapy response. In addition, there was no effect of this SNP on NSCLC survival, either in early stage or advanced NSCLC patients.

To the best of our knowledge, it is the first time that a significant association between PTPRD rs2279776 and NSCLC risk was observed. So far, there have been no studies investigating the association between PTPRD polymorphisms and NSCLC risk or prognosis. PTPRD is a putative tumor suppressor gene [4]. The PTPRD protein involves in a variety of cellular activities associated with tumorigenesis, including cell growth, differentiation, and oncogenic transformation. Our previous study has indicated that rs2279776 polymorphism in PTPRD gene is associated with the risk of ccRCC [6]. The $C$ allele of rs2279776 was associated with less PTPRD expression, thus affecting the protein function

Table 2: Association of PTPRD rs2279776 with NSCLC risk.

\begin{tabular}{|c|c|c|c|c|c|c|}
\hline & Cases, n (\%) & Controls, n (\%) & $P$ & OR $(95 \% \mathrm{CI})$ & Adjusted $P^{*}$ & Adjusted OR* $(95 \% \mathrm{CI})$ \\
\hline \multicolumn{7}{|l|}{ rs2279776 } \\
\hline GG & $161(45.7)$ & $379(53.8)$ & & 1.00 (reference) & & 1.00 (reference) \\
\hline GC & $153(43.5)$ & $264(37.5)$ & 0.03 & $1.36(1.04-1.79)$ & 0.02 & $1.40(1.05-1.87)$ \\
\hline $\mathrm{CC}$ & $38(10.8)$ & $61(8.7)$ & 0.09 & $1.47(0.94-2.29)$ & 0.31 & $1.28(0.79-2.06)$ \\
\hline GG & $161(45.7)$ & $379(53.8)$ & & 1.00 (reference) & & 1.00 (reference) \\
\hline $\mathrm{GC}+\mathrm{CC}$ & $191(54.3)$ & $325(46.2)$ & 0.01 & $1.38(1.07-1.79)$ & 0.02 & $1.37(1.04-1.81)$ \\
\hline G allele & $475(67.5)$ & $1022(72.6)$ & & 1.00 (reference) & & 1.00 (reference) \\
\hline C allele & $229(32.5)$ & $386(27.4)$ & 0.02 & $1.28(1.05-1.55)$ & 0.05 & $1.23(1.00-1.01)$ \\
\hline \multicolumn{7}{|l|}{ Smoking status } \\
\hline Never smokers & $170(48.3)$ & $570(81.0)$ & & 1.00 (reference) & & \\
\hline Ever smokers & $182(51.7)$ & $134(19.0)$ & $<0.001$ & $4.55(3.44-6.03)$ & & \\
\hline
\end{tabular}

Abbreviations: CI: Confidence Interval; OR: Odds Ratio.

*Adjusted for age and smoking status.

† Additive model

$\neq$ Dominant model

※ Allelic association test

a allele count 
Table 3: Stratified analyses of the association between PTPRD rs2279776 and NSCLC risk. Abbreviations: CI: Confidence Interval; OR: Odds Ratio.

\begin{tabular}{|c|c|c|c|c|}
\hline Stratified character & Cases, $\mathbf{n}(\mathbf{G G} / \mathbf{G C}+\mathbf{C C})$ & Controls, $\mathbf{n}(\mathbf{G G} / \mathbf{G C}+\mathbf{C C})$ & $\boldsymbol{P}$ & OR (95\% CI) \\
\hline Sex & & & $\mathbf{0 . 0 2}$ & $\mathbf{1 . 4 6}(\mathbf{1 . 0 7}-\mathbf{1 . 9 8})$ \\
\hline Male & $246(114 / 132)$ & $492(274 / 218)$ & 0.38 & $1.23(0.77-1.97)$ \\
\hline Female & $106(59 / 47)$ & $212(105 / 107)$ & \\
\hline Age & & & 0.12 & $1.33(0.93-1.92)$ \\
\hline$\leq 60$ years & $165(68 / 97)$ & $412(199 / 213)$ & $\mathbf{0 . 0 1}$ & $\mathbf{1 . 6 2 ( 1 . 1 2 - 2 . 3 6 )}$ \\
\hline$>60$ years & $187(93 / 94)$ & $292(180 / 112)$ & \\
\hline Smoking status & $170(82 / 88)$ & $570(306 / 264)$ & 0.21 & $1.24(0.88-1.75)$ \\
\hline Never & $182(79 / 103)$ & $134(73 / 61)$ & 0.05 & $1.56(1.00-2.44)$ \\
\hline Ever & & & \\
\hline
\end{tabular}

Table 4: Comparison of response rate according to different characteristics of patients in advanced NSCLC patients (N=161).

\begin{tabular}{|c|c|c|c|c|}
\hline Characteristic & $P R(n=44)$ & $S D+P D(n=65+52)$ & Response Rate (\%) & $\mathbf{P}^{*}$ \\
\hline rs2279776 & & & & 0.10 \\
\hline GG & 22 & 42 & $34.4 \%$ & \\
\hline $\mathrm{GC}+\mathrm{CC}$ & 22 & 75 & $22.7 \%$ & \\
\hline Gender & & & & 0.19 \\
\hline Male & 33 & 75 & $30.6 \%$ & \\
\hline Female & 11 & 42 & $20.8 \%$ & \\
\hline Age (year) & & & & 0.60 \\
\hline$>60$ & 22 & 53 & $29.3 \%$ & \\
\hline$\leq 60$ & 22 & 64 & $25.6 \%$ & \\
\hline Smoking Status & & & & 0.04 \\
\hline No & 14 & 59 & $19.2 \%$ & \\
\hline Yes & 30 & 58 & $34.1 \%$ & \\
\hline Histology & & & & 0.97 \\
\hline Adenocarcinoma & 14 & 38 & $26.9 \%$ & \\
\hline Squamous cell carcinoma & 23 & 59 & $28.0 \%$ & \\
\hline Other & 7 & 20 & $25.9 \%$ & \\
\hline Stage, n (\%) & & & & 0.93 \\
\hline IIIA & 2 & 6 & $25.0 \%$ & \\
\hline IIIB & 12 & 35 & $25.5 \%$ & \\
\hline IV & 30 & 76 & $28.3 \%$ & \\
\hline ECOG performance status & & & & 0.55 \\
\hline $0-1$ & 43 & 112 & $27.7 \%$ & \\
\hline$\geq 2$ & 1 & 5 & $16.7 \%$ & \\
\hline Radiation therapy & & & & 0.83 \\
\hline Never received & 24 & 66 & $26.7 \%$ & \\
\hline Ever received & 20 & 51 & $28.2 \%$ & \\
\hline
\end{tabular}

Abbreviations: ECOG: Eastern Cooperative Oncology Group; PD: progressive disease; PR: Partial Response; SD: Stable Disease.

* $\mathrm{P}$ values are derived by $\mathrm{x}^{2}$ test, except for ECOG performance status.

[6]. rs2279776 is a synonymous SNP which translates to the $1418^{\text {th }}$ amino acid in the first tyrosine phosphateses domain of PTPRD protein [8]. The synonymous change from GGC to GGG both encoding glycine alters substrate specificity with functional effects [9].

Lung cancer develops through the accumulation of various genetic alterations such as alterations in oncogenes and/or tumor suppressor genes. For example, about $50 \%$ of NSCLC has TP53 mutations [5]. It is important to identify more genes that are involved in lung carcinogenesis to design preventive strategies and improve the diagnosis and therapy of lung cancer. PTPRD protein can inhibit growth and cause apoptosis. Several mutations including certain nonsense mutations result in a production of truncated PTPRD proteins without the whole or a part of protein tyrosine phosphates catalytic domains [10]. It has been reported that the PTPRD locus at 9p23 was frequently deleted in NSCLC [11]. Studies also have found that homozygous deletions and mutations in the PTPRD gene are frequently 
observed in lung adenocarcinomas [12-14]. The epigenetic changes of PTPRD may also play a role in lung carcinogenesis. It is shown that the PTPRD gene is frequently subjected to promoter CpG island hypermethylation [4]. In addition, PTPRD may also act on carcinogenesis through its interaction with STAT3.

However, we did not observe any effect of PTPRD SNP rs2279776 on NSCLC treatment response or survival. There are several possible explanations. First, the effect of genetic polymorphisms is relatively moderate compared to other environmental factors such as smoking and radiation therapy. It is likely that we didn't detect the effect of PTPRD SNP due to these known or unknown factors. Second, we only tested one SNP in the current study, although evidences have shown the function of this SNP, it cannot represent the whole gene. Other SNPs of PTPRD gene need to be tested in future studies. On the other hand, we cannot rule out the possibility that PTPRD plays a role in the development of NSCLC but not cancer progression.

There are several limitations in the current study. First,

Table 5: Association between PTPRD rs2279776 or patient characteristics and overall survival in early stage NSCLC ( $\mathrm{N}=156)$.

Abbreviations: MST: Median Survival Time; ECOG: Eastern Cooperative Oncology Group

\begin{tabular}{|c|c|c|c|c|}
\hline \multirow[t]{2}{*}{ Characteristic } & \multicolumn{4}{|c|}{ Univariate } \\
\hline & $\mathbf{N}$ & $\begin{array}{c}\text { MST } \\
\text { (months) }\end{array}$ & $95 \% \mathrm{CI}$ & $\begin{array}{c}\text { Log-Rank } \\
\text { P }\end{array}$ \\
\hline rs2279776 & & & & \\
\hline GG & 79 & 63.1 & 11.9 to 114.3 & \\
\hline $\mathrm{GC}+\mathrm{CC}$ & 77 & 46.4 & 35.3 to 57.5 & \\
\hline Gender & & & & 0.17 \\
\hline Male & 109 & 46.4 & 32.3 to 60.5 & \\
\hline Female & 47 & 100.7 & -- & \\
\hline Smoking Status & & & & 0.01 \\
\hline No & 80 & 82.2 & 29.4 to 135.0 & \\
\hline Yes & 76 & 45.6 & 39.0 to 52.2 & \\
\hline Histology & & & & 0.25 \\
\hline Squamous cell carcinoma & 54 & 41.8 & 35.4 to 48.2 & \\
\hline Adenocarcinoma & 81 & 63.1 & -- & \\
\hline Other & 21 & 100.7 & 0.0 to 226.5 & \\
\hline Stage & & & & 0.09 \\
\hline I & 47 & 63.1 & -- & \\
\hline II & 73 & 57.6 & 23.0 to 92.2 & \\
\hline III & 36 & 39.3 & 31.7 to 46.9 & \\
\hline $\begin{array}{l}\text { ECGO performance } \\
\text { status }\end{array}$ & & & & 0.01 \\
\hline $0-1$ & 36 & 39.3 & 39.6 to 75.6 & \\
\hline$\geq 2$ & 2 & 12.5 & -- & \\
\hline Radiation therapy & & & & 0.43 \\
\hline Never received & 36 & 178.6 & -- & \\
\hline Ever received & 120 & 57.6 & 40.9 to 74.3 & \\
\hline
\end{tabular}

Table 6: Association between PTPRD rs2279776 or patient characteristics and overall survival in late stage NSCLC ( $\mathrm{N}=161)$.

Abbreviations: MST: Median Survival Time; ECOG: Eastern Cooperative Oncology Group

\begin{tabular}{|c|c|c|c|c|}
\hline \multirow[t]{2}{*}{ Characteristic } & \multicolumn{4}{|c|}{ Univariate } \\
\hline & $\mathbf{N}$ & $\begin{array}{c}\text { MST } \\
\text { (months) }\end{array}$ & $95 \% \mathrm{CI}$ & $\begin{array}{c}\text { Log-Rank } \\
\text { P }\end{array}$ \\
\hline \multicolumn{5}{|l|}{ rs2279776 } \\
\hline GG & 64 & 16.8 & 12.3 to 21.3 & \\
\hline $\mathrm{GC}+\mathrm{CC}$ & 97 & 18.6 & 11.4 to 25.8 & \\
\hline Gender & & & & 0.13 \\
\hline Male & 108 & 16.8 & 14.4 to 19.2 & \\
\hline Female & 53 & 20.4 & 13.3 to 27.5 & \\
\hline Smoking Status & & & & 0.04 \\
\hline No & 73 & 24.4 & 15.8 to 33.0 & \\
\hline Yes & 88 & 16.8 & 15.0 to 18.6 & \\
\hline Histology & & & & 0.29 \\
\hline $\begin{array}{l}\text { Squamous cell } \\
\text { carcinoma }\end{array}$ & 52 & 16.6 & 11.5 to 21.7 & \\
\hline Adenocarcinoma & 82 & 18.6 & 15.2 to 22.0 & \\
\hline Other & 27 & 25.0 & $\begin{array}{l}0.05 \text { to } \\
49.95\end{array}$ & \\
\hline Stage & & & & 0.32 \\
\hline IIIA & 8 & 22.3 & 9.5 to 35.1 & \\
\hline IIIB & 47 & 26.9 & 13.2 to 40.6 & \\
\hline IV & 106 & 17.7 & 15.0 to 20.4 & \\
\hline $\begin{array}{l}\text { ECGO performance } \\
\text { status }\end{array}$ & & & & 0.51 \\
\hline $0-1$ & 155 & 18.4 & 15.6 to 21.3 & \\
\hline$\geq 2$ & 6 & 22.3 & 9.2 to 35.4 & \\
\hline Radiation therapy & & & & 0.049 \\
\hline Never received & 90 & 16.2 & 13.4 to 19.0 & \\
\hline Ever received & 71 & 24.3 & 15.1 to 33.5 & \\
\hline
\end{tabular}

we only collected OS data but not lung cancer specific survival, and were not able to reliably denote cause of death. Second, the sample size is relatively small especially for the survival analysis, and we had a very low power to detect a true association. Finally, as we have mentioned above, the tumorigenic effects of PTPRD is complex, analysis of one single polymorphism cannot represent the whole picture.

In conclusion, to our knowledge, this is the first study provided evidences that PTPRD polymorphisms may be associated with an individual's susceptibility to NSCLC risk. Studies with larger sample sizes are needed to further investigate the role of PTPRD in cancer in general and lung cancer in specific.

\section{Acknowledgements}

This study was supported by Key Project of Shanghai Science and Technology Committee grant (06DZ19503 to G. Cao). 


\section{References}

1. Jemal A, Bray F, Center MM, Ferlay J, Ward E, et al. (2011) Global cancer statistics. CA Cancer J Clin 61(2): 69-90.

2. Lord RV, Brabender J, Gandara D, Alberola V, Camps C, et al. (2002) Low ERCC1 expression correlates with prolonged survival after cisplatin plus gemcitabine chemotherapy in non-small cell lung cancer. CA Cancer Res 8(7): 2286-2291.

3. Arriagada R, Bergman B, Dunant A, Le Chevalier T, Pignon JP, et al (2004) Cisplatin-based adjuvant chemotherapy in patients with completely resected non-small-cell lung cancer. N Engl J Med 350: 351-360.

4. Veeriah S, Brennan C, Meng S, Singh B, Fagin JA, et al. (2009) The tyrosine phosphatase PTPRD is a tumor suppressor that is frequently inactivated and mutated in glioblastoma and other human cancers. Proc Natl Acad Sci U S A 106(23): 9435-9440.

5. Kohno T, Otsuka A, Girard L, Sato M, Iwakawa R, et al. (2010) A catalog of genes homozygously deleted in human lung cancer and the candidacy of PTPRD as a tumor suppressor gene. Genes Chromosomes Cancer 49(4): 342-352.

6. Du Y, Su T, Tan X, Li X, Xie J, et al. (2013) Polymorphism in protein tyrosine phosphatase receptor delta is associated with the risk of clear cell renal cell carcinoma. Gene 512(1): 64-69.

7. Therasse P, Arbuck SG, Eisenhauer EA, Wanders J, Kaplan RS, et al (2000) New guidelines to evaluate the response to treatment in solid tumors. European Organization for Research and Treatment of Cancer, National Cancer Institute of the United States, National Cancer
Institute of Canada. J Natl Cancer Inst 92(3): 205-216.

8. Shyur SD, Wang JY, Lin CG, Hsiao YH, Liou YH, et al. (2008) The polymorphisms of protein-tyrosine phosphatase receptor-type delta gene and its association with pediatric asthma in the Taiwanese population. Eur J Hum Genet 16(10): 1283-1288.

9. Kimchi-Sarfaty C, Oh JM, Kim IW, Sauna ZE, Calcagno AM, et al. (2007) A "silent" polymorphism in the MDR1 gene changes substrate specificity. Science 315(5811): 525-528.

10. Lafarge S, Sylvain V, Ferrara M, Bignon YJ. (2001) Inhibition of BRCA1 leads to increased chemoresistance to microtubule-interfering agents, an effect that involves the JNK pathway. Oncogene 20(45): 6597-6606.

11. Sato M, Takahashi K, Nagayama K, Arai Y, Ito N, et al. (2005) Identification of chromosome arm $9 \mathrm{p}$ as the most frequent target of homozygous deletions in lung cancer. Genes Chromosomes Cancer 44(4): 405-414

12. Weir BA, Woo MS, Getz G, Perner S, Ding L, et al. (2007) Characterizing the cancer genome in lung adenocarcinoma. Nature 450(7171): 893898.

13.Zhao X, Weir BA, LaFramboise T, Lin M, Beroukhim R, et al. (2005) Homozygous deletions and chromosome amplifications in human lung carcinomas revealed by single nucleotide polymorphism array analysis. Cancer Res 65(13): 5561-5570.

14.Ding L, Getz G, Wheeler DA, Mardis ER, McLellan MD, et al. (2008) Somatic mutations affect key pathways in lung adenocarcinoma. Nature 455(7216): 1069-1075 